\title{
COVID-19 PANDEMIC VS. PUBLIC TRANSPORT ATTRACTIVENESS: LITERATURE RESEARCH AND SELECTED SOLUTIONS AND RECOMMENDATIONS
}

\author{
Jan Fronek, Jaroslav Chlumecky, Daniel Vymetal ${ }^{1}$
}

\begin{abstract}
This paper deals with a literature search of authors dealing with public transport and the decline in passenger demand during the ongoing COVID-19 pandemic. The recommendations and conclusions of this article serve as a partial basis for the elaboration of dissertations, the topic, content and goal of which will respect and respond to this ongoing situation concerning the pandemic.
\end{abstract}

Keywords

public transport, demand for transport, competitiveness, epidemy

\section{INTRODUCTION}

Public transport in urban areas and in their agglomerations is an essential part of mobility and life in municipalities and cities with a larger population. Many global public transport systems increase the competitiveness of cars through various instruments, such as synergies between modes of transport, unification of tariffs, transport conditions, interconnection of individual public transport subsystems and, last but not least, connections to suburban or regional transport. However, there is no city in the world in which it would be possible to completely eradicate individual car transport, and it is therefore necessary, in the sense described above, to address the connection of public transport to the individual through various smart solutions.

Transporting more passengers at once in one means of transport has its advantages, such as reducing the occupation of traffic space or improving the ecological situation in cities. However, the mass transport of several public transport customers in one means of transport has one weakness, which has often been inflected in the last year.

This is the transmission of the COVID-19 disease, which is currently spreading in places with a higher number of people, to which public transport is an integral part. Few would have thought in the past that, although urban passenger transport has such a strong upward trend, it will be necessary to reduce it in a targeted manner and to try to reduce mobility precisely because of people-to-people contacts, which are undesirable in controlling and dealing with epidemics. This article addresses the facts caused by the unfavourable epidemiological situation and the effort to reduce mobility in public transport and tries to point out possible solutions in a certain regeneration of this service, which is currently perceived as not very attractive.

\footnotetext{
${ }^{1}$ University of Pardubice, Faculty of Transport Engineering, Studentská 95, 53210 Pardubice, Czech Republic Corresponding author, e-mail: daniel.vymetal@student.upce.cz
} 


\section{CONSEQUENCES OF THE COVID-19 PANDEMIC ON PUBLIC TRANSPORT}

The situation in public transport, which has affected it in the same way as other sectors of the secondary and tertiary sectors, is something that is very little studied. It is an issue with a history dating back to the winter of the turn of 2019 and 2020. Based on this, it is logical that there are only a small number of literary sources, articles and studies in this context (practically only units, tens at most). One of them is research and study in the source (Gkiotsalitis, 2020). The authors deal with the effects of the COVID-19 pandemic on the demand in public transport.

Most of the information provided by selected sources relates to the first wave of the pandemic, which dates in the Czech Republic to approximately March - May / June 2020. The second wave of the pandemic then dates from about September 2020, with no end date. In the Czech Republic, it can be said that the number of waves is equal to the number and length of the declared state of emergency (Wikipedia, 2021). From other points of view, it is assumed that the number of pandemic waves is higher and the declaration of a state of emergency does not correspond to this. The data contained in the work are from the already "finished" first wave of the pandemic, while from the second as yet unfinished wave may not be available (MZČR, 2021).

The authors partially compare the current situation with a change in approach to public transport, for example after the terrorist attacks of 11 September 2001 or the SARS pandemic in 2000. Although these events did not significantly change travel patterns, they did contribute to changing security levels.

Hughes point to a decrease in public transport passengers during lockdowns (during pandemy) of up to $90 \%$ in public transport systems in the USA or China. Cities in the UK fell by $70 \%$, with cities in the Netherlands, Hungary and France falling between $85 \%$ and $95 \%$ (Hughes 2020). Many public transport systems around the world have halted, significantly reduced or imposed strict operating conditions so as to minimize the number of passengers and significantly reduce the number of reasons why passengers can be transported by public transport. (exclusion of transport for passengers, e.g. tourism, etc.) Gkiotsalitis also conducts research from sources dealing with the study of the probability of COVID-19 transmission in public transport, which is precisely due to significant restrictions on population mobility by this mode of transport (Gkiotsalitis, 2020). Some sources indicate a higher risk of transmission in vehicles with air conditioning, others point to the need for frequent ventilation of both vehicles and closed station lobbies. An important parameter is also the time spent with a potential vector in one vehicle. In addition to the above, it is very important to keep the distances, which, however, cannot be ensured in all cases in public transport, especially in non-rail subsystems of public transport. The authors arrived at an occupancy value of only $6.5 \%$ of the offered capacity in Washington metro vehicles so that the spacing of at least 2 meters was maintained. This is about 16 times less possible occupancy of the vehicle than in normal situations. Gkiotsalitis also dealt with the form of public transport planning in precisely the situations that have occurred, and still occur as a result of the COVID-19 pandemic. The measures implemented after the start of the pandemic were for crisis managers of transport companies without significant previous experience (a similar situation has never occurred since the Spanish flu, but then public transport was not as developed as it is today) and had to be addressed on an ad hoc basis. Furthermore, this article addresses the hierarchy of public transport planning in similar situations, which is the middle ground between providing basic transport services, even distribution of individual connections, security solutions against possible infection, general passenger costs (e.g. waiting times) and operating costs (e.g. transport performance, number of vehicles). Planning is both operational (short-term) and tactical and strategic. Operational planning is, for example, an immediate reduction in traffic at a given moment, a limitation on the maximum number of passengers in means of transport or at the entrances to the vestibules of a city railway. Tactical planning is the solution of timetables, intervals between connections or capacity options of transfer terminals and places with higher passenger aggregation. Strategic planning in this sense is longterm planning in the nature of construction and technical solutions for public transport infrastructure. It is 
planning for the future, which in 2020, when the pandemic situation began to affect this service, were not available to public transport operators and they had to work with existing infrastructure.

Beck address the view of public transport during the COVID-19 pandemic from a slightly different perspective (Beck 2020). The authors of this article point out the significant risk in the attractiveness and use of public transport in the future in terms of a strong increase in the so-called home office, which was joined by a number of companies, mainly in the tertiary sector of the economy. The authors search for the issue of work from home, its advantages and disadvantages and the gradual development from history to the present. A survey was conducted among the population of Australia on the popularity of so-called home offices from the perspective of both employers and employees. The increase in work from home was almost $23 \%$ in the monitored area during the first wave of the pandemic 5 days a week, while the decrease in work away from home was $32 \%$ throughout the week. The authors point out that it is necessary to take this issue into account when planning transport services and the frequency of public transport supply, and at the same time predict a general increase in people working from home in the future, which will have a significant impact on public transport demand.

The impact on public transport and mobility in cities before and during the COVID-19 pandemic is also addressed in European transport research review where Anke conducted a mobility survey in Germany. The authors came to interesting values, where, for example, 57-63\% of respondents do not feel well in public transport (in response to the risk of infection), $6 \%$ of respondents who do not own a car are considering buying it. Furthermore, a modal split was performed between the means of transport used for commuting, to school and for other reasons. It is interesting to compare the modal split between the urban area and the rural area, as already indicated by the graphs in the figure below (Anke 2021).
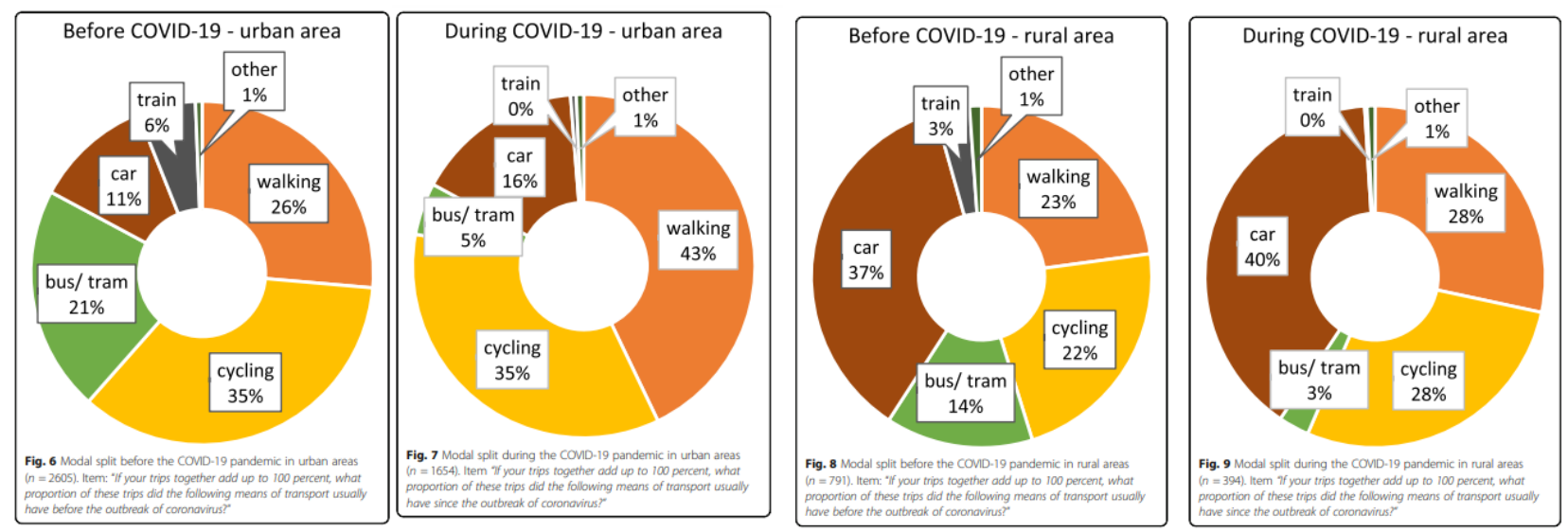

Fig. 1 Modal split before/during COVID; Anke, 2021

It is clear from their survey that a number of respondents using short-distance public transport, especially in cities, chose pedestrian transport as a result of the pandemic. Accordingly, there is also a noticeable increase in walking by $17 \%$. Roughly, $5 \%$ of respondents to the survey then used the individual one instead of public transport in cities. On the contrary, in the countryside, along with walking, the share of bicycle traffic also increased.

In their article, the authors point out the opposite consequences. Increasing the share of walking and cycling has essentially had a positive effect on both sustainable mobility and the climate and health. On the other hand, this goes hand in hand with increasing mobility through cars, to which some respondents switched from public transport. Anke point out that it is necessary for urban systems as well as suburban and regional systems to get passengers to use public transport again to the greatest extent possible, both by means of more favourable fares, by reducing time coupons and by a higher appeal for hygiene and disinfection of mobile and stable elements of public transport. 


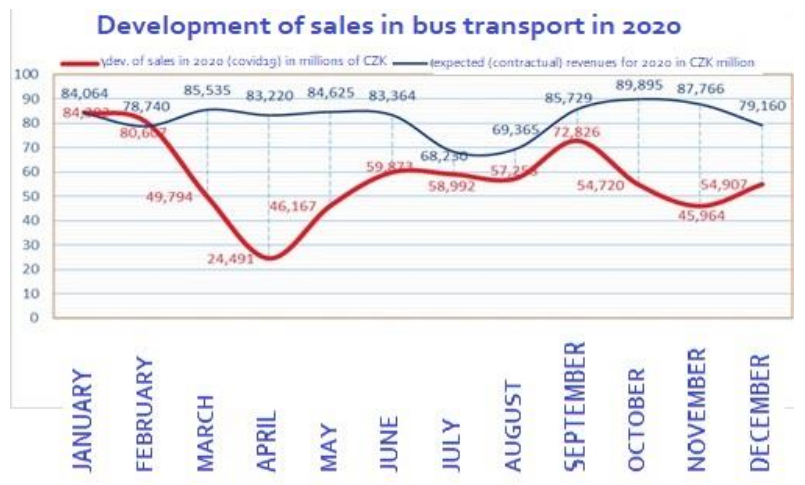

Fig. 2 Development of sales in bud transport in 2020 (Prague); ROPID, 2021

From the point of view of the Czech Republic, in which this search is processed, there is, for example ROPID points to a significant decline in sales in the Czech Republic, specifically to declines in the Central Bohemian Region in the integrated transport system Prague Integrated Transport (PID - Pražská Integrovaná Doprava). Instead of expected revenues in suburban and regional bus transport in April 2020 in the amount of CZK 83.22 million (approx. EUR 3.2 million), actual revenues were CZK 24.49 million (approx. EUR 0.95 million).

\section{SELECTED SOLUTIONS AND RECOMMENDATIONS FROM THE POINT OF VIEW OF PUBLIC TRANSPORT PREFERENCE}

Closely related to the restriction of public transport due to the COVID-19 pandemic is the issue of public transport preferences, both the direct and more intensely affected situation affects indirect preferences, which includes part of the chapter on integrated transport systems described below, or the issue of tariffs, time coupons, etc. Direct preference for public transport, which according to Gardner is divided into physical measures, measures on light signalling devices and integrated measures (Gardner, 2009). Restrictions on public transport due to the COVID-19 pandemic and its consequences have an impact mainly on physical measures, specifically on reserved lanes, which are one of the most common direct preferential measures in favour of urban public transport over individual public transport (IPT). Due to the fear of infection and the general fear of the accumulation of more people in a small area, it can be assumed that there will be an increase in individual traffic. The proof is also the already mentioned in study Impact of SARS-CoV-2 on the mobility behaviour in Germany, where the increase in car traffic in cities is $5 \%$ after the first wave of the pandemic (Anke, 2021). Permanently reserved lanes reduce the capacity of local roads and in the event of an increase in IPT and at the same time increasing the infrastructure of reserved lanes for public transport, there will probably be an overall slowdown in urban traffic, increase emissions and increase the likelihood of violating the ban on IPT vehicles in public lanes. A compromise can be the so-called intermittent lanes, which are dealt with, for example in the study The intermittent Bus Lane signals setting within an area (Viegas, 2004) and in the study Demonstration and evaluation of an intermittent bus lane strategy (Chiabaut, 2019). At the same time, in response to the expected increase in mobility in the city through IPT, it is necessary to consistently monitor and consider reducing the capacity of local roads by transport vehicles.

\section{SELECTED SOLUTIONS AND RECOMMENDATIONS FROM THE PERSPECTIVE OF INDIVIDUAL PUBLIC TRANSPORT}

The decline in public transport connections and the deterioration of transport services in space and time, results in the diversion of ordinary users. Unfortunately, the deterioration in transport services is most affecting rural areas and thus people who commute to work in cities. For these inhabitants, it can be assumed that there will be a change in the modal split in favour of individual car transport, which has 
a clear negative impact on urban agglomerations themselves for several reasons - the primary reason is the emergence of further pressure on traffic at rest, which is already due to reduced fluctuation of cars in parking spaces, in many cities on the border of sustainability - the secondary reason is the increase in emission load (noise and dust) due to the fact that the driver must travel a greater distance in search of a free parking space.

At first glance, it might seem that the situation is only temporary and that these inhabitants will return to public transport. However, this can be very misleading. A study of traffic behavior change due to COVID19 , conducted in the Polish city of Gdańsk, shows that only $74 \%$ of former public transport users would resume public transport after restrictions (Przybylowski, 2021). However, it must be borne in mind that prolonged restrictions on public transport will lead to a reduction in this figure, mainly for several reasons. First, the ongoing pandemic will dramatically increase the cost items in state budgets, which, hand in hand with the lockdown tax shortfall, will result in cuts in state budgets and cuts in public funding. This will result in a reduction of connections across timetables, which will again affect the choice of passengers who, thanks to sparse transport services not only in space, but especially in time, reach for individual car transport. This will mean a further decline in the collection of sales in transport companies and a subsequent further reduction of connections. The second reason is the simple habit of passengers, the influence of which on passengers' decisions should not be underestimated.

If traffic restrictions last for too long, it is necessary to think about the cooperation between individual road transport and regional public transport and to proceed in three-time levels - operational, tactical and strategic. The operational level solves the reduction of low-traffic regional lines and significantly strengthens the backbone lines, especially city lines serving $P+R$ car parks, where it ensures the connection of IPT with public transport. The tactical level increases the number of IPT hotspots with significant regional (especially rail) transport links within the region, so as to allow passengers to connect with the metropolitan area. And that under the conditions of frequent, fast and reliable connections. The strategic level then includes the construction of full-fledged $\mathrm{P}+\mathrm{R}$ car parks with all the necessary infrastructure (toilets, waiting rooms, vending machines, etc.) at these points of elevation, so that passengers feel comfortable when returning to public transport.

\section{SELECTED SOLUTIONS AND RECOMMENDATIONS FROM THE POINT OF VIEW OF INTEGRATED TRANSPORT SYSTEMS}

The ongoing COVID 19 pandemic has also affected the area of integrated transport systems, which is closely linked and interconnected with public transport as such, especially in the sense that within integrated transport systems the connections of individual connections, uniform tariff issues and provision of transport services are addressed. . The overall decline in demand from passengers (whether due to the so-called home office, distance learning for students, inability to travel for recreation or entertainment or even for fear of infection in a public transport vehicle) does not benefit these systems at all. Many connections are cancelled due to low load and some connections may be untied. Due to the loss of sales, fare increases are often considered, which as a result may cause a further (albeit already milder) decrease in transported passengers. Many passengers will also stop public transport under the integrated transport system due to fears of infection and contact with other people in a relatively small area of the vehicle. The partial recommendations in this area are the following:

1. If part of the lines has to be cancelled, it should take place in such a way as to ensure functional connections between the lines (albeit in smaller numbers).

2. Disruption of connections should not occur where demand is sufficient, as after the cancellation of part of the connections, passengers would be more cumulative in the vehicles of existing connections. 
3. If there is an increase in the fare within the integrated transport system, this increase should be proportionate so as not to discourage passengers from using public transport and at the same time such that there is no need for further necessary increases in the foreseeable future.

4. Carriers and integrated transport operators should reassure passengers of the safety of public transport so that they do not have to worry about travel and, of course, should adequately ensure that vehicles are sufficiently disinfected and that all public hygiene measures are complied with.

\section{CONCLUSIONS}

The article summarized selected sources from authors dealing with public transport and the related decline in demand and changes in customer behavior during the COVID 19 pandemic compared to before it. The authors of this article envisage another study that would compare data on the use of public transport in the Czech Republic in the period before the COVID19 pandemic, during the first and subsequently during the second wave of the pandemic. At the time of writing this article, the second wave of the pandemic had not yet ended in the Czech Republic, so it was not possible to obtain this data, compare it and then interpret it appropriately. The research and the conclusions of this article serve as a partial basis for the elaboration of dissertations, the topic, content and goal of which will respect and respond to this ongoing situation concerning the pandemic.

Many sectors and activities of our lives are currently heavily affected by the COVID 19 pandemic, including public transport. The decline in the use of public transport is significant and so it is necessary to address these impacts and to some extent prevent them. This article makes some recommendations, namely in the area of public transport preferences (eg. creation of intermittent segregated lanes for public transport), in the area of IPT (eg. creating a better connection of public transport to P + R car parks) and in the area of integrated transport systems (eg. continuity of connections where there is sufficient demand, increase fares in a reasonable manner and reassure the public of safety when traveling by public transport).

\section{References}

Juliane, A., Francke, A., Schaefer, L-M., a Petzoldt, T. 2021. Impact of SARS-CoV-2 on the mobility behaviour in Germany. European Transport Research Review, ISSN 1867-0717. doi: 10.1186/s12544-021-00469-3

Beck, Matthew J, David A. Hensher a Edward WEI, 2020. Slowly coming out of COVID-19 restrictions in Australia: Implications for working from home and commuting trips by car and public transport. Journal of Transport Geography, ISSN 0966-6923. doi: 10.1016/j.jtrangeo.2020.102846

Gardner, K., D’Souza, C., Hounsell, N., Shrestha, B. a Bretherton, D. 2009. Interaction of buses and signals at road crossings: Review of Bus Priority at Traffic Signals around the World [online]. April. [quot. 201911-22]. Available from: http://content.tfl.gov.uk/interaction-of-buses-and-signals-at-road-crossings.pdf

Gkiotsalitis, Konstantinos a Oded Cats. Public transport planning adaption under the COVID-19 pandemic crisis: literature review of research needs and directions. Transport Reviews [online]. DEC 20, 1-19 [cit. 2021-03-16]. ISSN 0144-1647. Available from: doi: 10.1080/01441647.2020.1857886

Przybylowski, A., Stelmak, S., Suchanek, M. 2021. Mobility Behaviour in View of the Impact of the COVID19 Pandemic-Public Transport Users in Gdansk Case Study. Sustainability 2021, 13, 364. https://doi.org/10.3390/su13010364

Viegas, J. a LU, BC. 2004. The Intermittent Bus Lane signals setting within an area [online]. Doi: 10.1016/j.trc.2004.07.005. 453-469. Available from: http://apps.webofknowledge.com /full_record.do?product=WOS\&search_mode=GeneralSearch\&qid=43\&SID=E5HjCLciSSbasUntMFS\&page $=1 \& \mathrm{doc}=1$ 
Chiabaut, N. a Barcet, A. 2019. Demonstration and evaluation of an intermittent bus lane strategy [online]. doi: $\quad 10.1007 / \mathrm{s} 12469-019-00210-3 . \quad 443-456 . \quad$ Available from: http://apps.webofknowledge.com/full record.do?product=WOS\&search mode=GeneralSearch\&qid=1\&S ID=E4xkbhmKjj6NqXwqz6u\&page $=1 \&$ doc $=$

Hughes, T. 2020. Poor, essential and on the bus: Coronavirus is putting public transportation riders at risk. USA TODAY. Available from: https://eu.usatoday.com/story/news/nation/2020/04/14/publictransportation-users-risk-coronavirus-spreads-across-us/2979779001/

Koronavirus. Ministerstvo zdravotnictví České republiky [online]. Praha: Ministerstvo zdravotnictví České republiky, 2021 [quot. 2021-3-23]. Available from: https://koronavirus.mzcr.cz/

Náklady na dopravu jsou neudržitelné. Pražská integrovaná doprava [online]. Praha: ROPID, 2021 [cit. 2021-3-23]. Dostupné z: https://pid.cz/naklady-na-dopravu-jsou-neudrzitelne-kraj-pristupuje-kestabilizacnim-opatrenim/

Nouzový stav v Česku. Wikipedia: the free encyclopedia [online]. San Francisco (CA): Wikimedia Foundation, 2001- [quot. 2021-3-23]. Available from: https://cs.wikipedia.org/wiki/Nouzový_stav_v_Česku 